\title{
Creating a pathway to employability in a Business School: developing professional practice through collaboration
}

Katherine Leopold, Dawn Reilly

University of Greenwich

\begin{abstract}
Within Business Education, our students study technical skills and gain commercial knowledge which will equip them for their future careers. In addition, our students need to develop the 'soft skills' which employers are looking for when they recruit graduates. To create a pathway to employability, we have used a collaboration between a module leader and a Business School employability consultant to support second year students. We set out how we have included the consultant in planning and delivering specific topics within the module, and in giving formative feedback to students. In this way we have embedded employability skills in the curriculum and built a relational pathway to the Business School's careers support for students.
\end{abstract}

Keywords: Business Education, collaboration, employability, formative assessment, teamwork

\section{Introduction}

This case study describes how we have used collaboration to support second year students studying an accounting degree with an Information Systems (IS) focus in the Business School at the University of Greenwich. Students on business-related programmes are acquiring knowledge and developing skills which are of interest to employers. Here, as IS specialists, much of the students' time is spent in computer labs where they learn technical skills which equip them for their future careers as the graduates of tomorrow. However, the broadening competition for 'talent' in industry means that our employability skills development must deliver on two additional fronts: internally, in order to enhance the student experience; and externally, producing students who have the transferable skills they need in order to be ready for graduate employment opportunities.

Despite the consensus that developing employability skills is important, what constitutes a successful set of 'employability skills' is the subject of considerable discussion and there can be tension around where it should 'fit' in the academic curriculum (Di Pietro, 2017; McQuaid and Lindsay, 2005; Wilton, 2012). Tan and Laswad (2018) argue that employers are increasingly treating soft skills on a par with academic achievement. Their analysis of Australian and New Zealand job advertisements demonstrates that employers value accountants' teamwork and interpersonal skills, including the ability to present and discuss views. The Office for Students (2018: 3) states the following:

We want to ensure that students leave their courses with the knowledge, qualifications, skills and attributes that are required by employers, both now and into the future ... 
Within an IS degree programme, opportunities to work in teams and to discuss ideas with their peers, thereby increasing students' 'soft' employability skills, can be restricted. To address these potential shortcomings in the programme, the students study a core Financial Analysis and Professional Practice single semester module in their second year. The Financial Analysis element includes researching corporate information using online sources consistent with their degree's focus on IS; the Professional Practice element includes teamwork and presentation skills.

Placement years undertaken by business and management students can have a positive impact on graduate outcomes (Wilton, 2012). However, our students may perceive that there are barriers to applying for placements (Shepherd and Sumner, 2018). For example, students are focussed on their university studies and dealing with assessment deadlines so thinking about placements and completing application forms may not be their priority. Also, students can lack confidence that their application will be successful. Therefore, it is important that we encourage second year students as much as possible in this area and the module provides the opportunity to create a pathway for them to the Business School's employability support service.

\section{Design}

The aim of the Financial Analysis and Professional Practice module is to provide students with the knowledge and skills needed to perform an in-depth evaluation and comparison of a company's performance. Results are presented via a three-stage portfolio of linked assessments: an initial individual report; a group presentation; and a final individual report. The module has approximately 30 to 40 students each year.

In 2018-19 we reviewed the delivery of the module in order to embed employability clearly in the module through content and via meaningful interaction with a representative of the Business School's careers service. To enhance the employability content of this core module, the module leader brought an employability consultant onto the module team. In collaboration, the module leader and consultant planned the schedule for the term. The consultant planned and delivered sessions on teamwork and presentation skills. She also provided formative feedback to students on the group presentations which the students were required to make as part of the assessment structure.

\section{Professional Practice Session 1: Working in a team}

This session had immediate relevance for the students because they were starting work on a group presentation. Developing teamwork skills is a complex activity because simply discussing it in abstract results in students presenting idealised versions of teamwork which they do not then experience. The class started with a Mentimeter exercise to establish students' current understanding of what makes a good team and the consultant then discussed their ideas (Figure 1).

Having set up a theoretical context for teamwork, the session moved into a very practical Lego teambuilding exercise. Working with Lego enables teamwork to be experienced without the pressure of required prior knowledge and therefore it creates a more level playing field in the team. The students were given random assortments of bricks and instructed to build 'the tallest tower', using their planning time to communicate and then using minimal communication once building had started. They ignored the second instruction. Once the winner had been announced, there was a discussion about whether their teams had shown 
the elements that they had collated in Mentimeter and many students acknowledged that they had not. The class asked for a re-run of the exercise and entered into that enthusiastically, driven by the element of competition between groups.

The consultant then discussed with the class how what they had demonstrated during the exercise would have meant that they performed well at an assessment centre, drawing out what employers are looking for. This linked their skills and experience to something which students can be cautious about tackling.

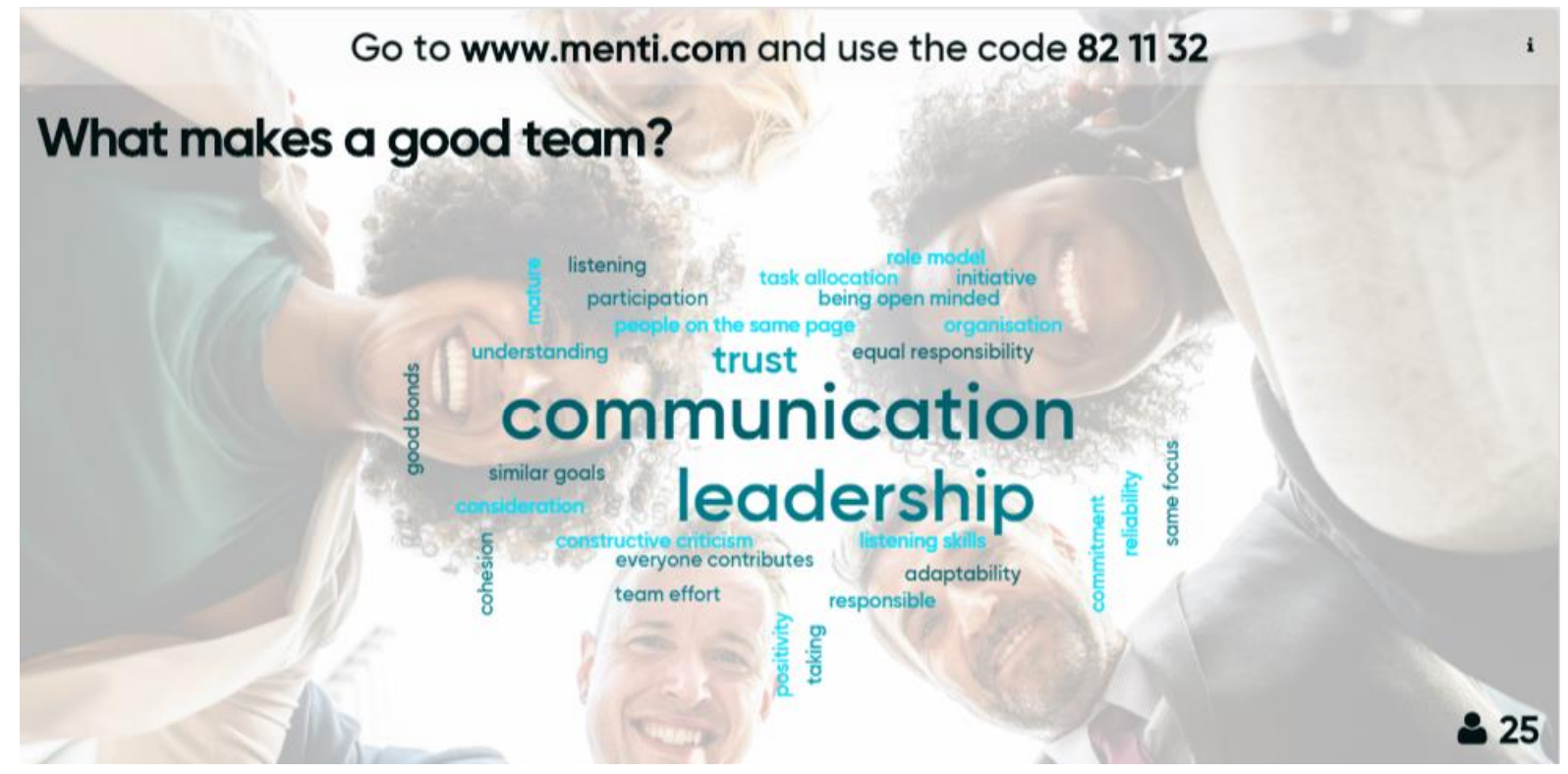

Figure 1: Mentimeter results

\section{Professional Practice Session 2: Delivering a successful presentation}

This session began with a short PowerPoint introduction to the topic by the employability consultant which provided a real-life demonstration of an effective presentation. Students then worked in their groups to create and tell a short fairy story. Each story was based on three random images provided by the consultant and were abstract, non-culturally dependent and open to multiple interpretations. Choosing this as the vehicle meant that the introduction to the session which talked about what makes a good presentation in theory could be put into immediate practice because it required no input from the Financial analysis case study within the module. The students engaged with the task they were given and demonstrated considerable imagination, and teamwork skills, as they tackled the task together.

In the whole class discussion which followed the group presentations, most students used the opportunity to talk to the consultant about their nervousness with interview presentations. However, the well-deserved praise and positive feedback they received from both the module leader and the consultant boosted their confidence. The consultant then talked to the class about placement years and encouraged them to apply. 


\section{Formative feedback in the employability office}

Our aim was to build a pathway for our students into the Business School Employability Office. This pathway was to be both relational and physical. Conversations with students about their work help to build relationships and therefore the consultant gave verbal feedback to students on their mock presentations before the actual summative assessment presentation sessions with the module leader. The aim of the feedback was not for the consultant to comment on the technical Financial analysis content but rather to focus on slide design and the way the group was working together. These conversations enhanced the relationships which had already been built through the consultant's delivery of the teamwork and presentation sessions. The feedback was delivered in scheduled face-to-face group meetings in the Employability Office in order to build a 'physical' bridge to our employability support for students. In their first year, students had been encouraged to visit and engage with the Employability Office within their professional development module. We wanted to remind the students about the location and encourage renewed interaction with the support provided.

Bringing students to the Business School Employability Office to talk about their presentations demonstrated that this was a safe place to go, even if the finished product was not ready to be reviewed. This mirrored the situation for students with incomplete job applications, cover letters and curricula vitae who might be unsure if they could seek help on their drafts from the consultant and her colleagues. The meetings also gave the consultant the opportunity to talk about placement applications in small groups thereby removing the pressure of a one-to-one conversation but still able to focus on the needs and interests of individual students.

\section{Implementation}

It was important that the module leader and employability consultant communicated frequently throughout the project and that the students knew that the content delivered by the consultant was an important part of the module and not 'extra-curricular'. The module leader therefore attended the teamwork and presentation skills sessions. The module leader also organised the mock presentation schedule and informed students about their group's appointment. Only one group did not attend this appointment although the student who did attend from that group then accessed employability support and secured a placement so his frustration at the team was mitigated by the longer-term outcome. After the feedback sessions, the consultant briefed the module leader on her conversations with students, identified non-attenders for follow up by the module leader, and referred any questions that had arisen on technical content.

\section{Evaluation and limitations}

The way in which we redesigned the delivery of the module in 2018-19 provided a good student experience. $92 \%$ of students who completed the end of module online survey agreed that they were satisfied with the teaching on the module and $92 \%$ also agreed that the module has helped to enhance the skills and knowledge needed after graduation. One student commented as follows on her experience of bringing the employability consultant into the module: 
$X$ 's input was refreshing (nice to have a break from the academic side) and helpful. She gave good pointers on the presentation. Was nice to meet her as well, as I feel comfortable to go to her to ask for any job application help.

Benefits from this collaborative approach between the module leader and employability consultant included the opportunity to promote placements within the module facilitating conversations with second year students and giving them encouragement to apply. Reflecting on whether we achieved this aim, we know that several students did go on to apply for placements and some secured a role. Looking ahead, as this cohort moves into the final year of the programme, they can also benefit from the pathway which the module has built to the Business School Employability Office through relationship with a named individual. In addition, it is hoped that students' confidence in their ability to perform well in an area such as giving a presentation where they do not consider themselves strong will help them have the confidence to apply for graduate schemes and graduate roles earlier. This would increase their chances of securing professional roles immediately after graduation.

This case study has set out our experience for the first year of collaborating in this way. Based on student feedback and the module leader's and consultant's observations of the good level of engagement with the module and the employability initiatives within it, we do not propose any major changes in the second year. One point to note however is that there will be a larger number of students on the module next year. This will not cause any major resourcing issues but it is acknowledged that for a very large cohort, the small group feedback on mock presentations might become challenging to arrange. However, the delivery of the whole class sessions on teamwork and presentations by an employability consultant would continue to be possible.

The module in this case study includes Professional Practice in its content and this facilitates collaboration with employability colleagues. In the module we were able to promote the transferable skills of working in a team and presenting with confidence in a novel way for business students on a programme with a technical focus. In other modules, the opportunities for collaboration might not be as obvious but where a module includes group work or a presentation, skills which until now might have been introduced by the module team, there can be an opportunity for this type of content to be delivered by colleagues from our careers services. In this way we are able to create pathways for students to employability.

\section{Reference list}

Di Pietro, G (2017), Degree classification and recent graduates' ability: Is there any signalling effect?, Journal of Education and Work, 30(5), 501-514, [online] available at: https://www.tandfonline.com/doi/full/10.1080/13639080.2016.1243230 (Accessed 8 September 2019)

McQuaid, R and Lindsay, C (2005), The concept of employability, Urban Studies, 42(2), 197-219.

Office for Students (2018), Office for Students Strategy 2018 to 2021, [online] available at: https://www.officeforstudents.org.uk/media/465d993d-daa8-42d2-a875-4a5fe63b211b/ofsstrategy-2018-21.pdf (Accessed 8 September 2019) 
Shepherd, A and Sumner, M (2018), Year in Industry: Barriers, Challenges and Motivations Project Report, [online] available at: http://teachingexcellence.leeds.ac.uk/wpcontent/uploads/2018/11/Year-in-Industry_Barriers-challenges-and-motivations_ProjectReport_Final.pdf (Accessed 28 July 2019)

Tan, L and Laswad, F (2018), Professional skills required of accountants: What do job advertisements tell us?, Accounting Education, 27(4), 403-432

Wilton, N (2012), The impact of work placements on skills development and career outcomes for business and management graduates, Studies in Higher Education, 37(5), 603-620, [online] 